\title{
Pharmacist Practice of Forensic Pharmacy Services
}

\author{
Yousef Ahmed Alomi*, iD BSC. \\ Pharm, MSc. Clin Pharm, BCPS, BCNSP, DiBA, \\ CDE, Critical Care Clinical Pharmacists, TPN \\ Clinical Pharmacist, Freelancer Business \\ Planner, Content Editor, and Data Analyst, \\ Riyadh, SAUDI ARABIA.
}

Mawadah mohsen aqeeli, Pharm D, Ministery of Heath, Abha, SAUDI ARABIA.

Rehab Sultan Najmi, Bsc. Pharm, King Khalid University Abha, SAUDI ARABIA. Samiyah Ibrahim Qassadi,

Pharm D, Jazan University, Jazan, SAUDI ARABIA.

\section{Correspondence:}

Dr. Yousef Ahmed Alomi, Bsc. Pharm, Msc. Clin pharm, BCPS, BCNSP, DiBA, CDE Critical Care Clinical Pharmacists, TPN Clinical Pharmacist, Freelancer Business Planner, Content Editor and Data Analyst, P.O.BOX 100 Riyadh 11392, Riyadh, SAUDI ARABIA.

Phone no: +966 504417712

E-mail:yalomi@gmail.com
Received: 14-11-2020;

Accepted: 04-02-2021;

Copyright: () the author(s), publisher and licensee International Journal of Pharmacology and Clinical Sciences. This is an open-access article distributed under the terms of the Creative Commons

Attribution Non-Commercial License, which permits unrestricted non-commercial use, distribution, and reproduction in any medium, provided the original work is properly cited.

This is an open access article distributed under the terms of the Creative Commons AttributionNonCommercial-ShareAlike 4.0 License

\section{Access this article online}

\begin{tabular}{|c|c|}
\hline & www.ijpcs.net \\
\hline & DOI: \\
\hline
\end{tabular}

\begin{abstract}
Goal: The current study expected to demonstrate the forensic pharmacy practice in the Kingdom of Saudi Arabia. Methods: It is an analysis of a cross-sectional study. An electronic survey was dispersed to all pharmacists and pharmacy interns. All students were omitted from the existing study. The survey consisted of demographic data about responders and practice aspects and implementations of forensic pharmacy. All analysis was completed using Microsoft Excel and Statistical Package of Social Science (SPSS), and Survey monkey. Results: The total number of responding pharmacists was 402. Of those, 198 (49.75\%) were male, while 200 (50.25\%) were female, with statistical significance between them $(p<0.001)$. Almost threequarters of the pharmacists had bachelor's degrees $303(75.56 \%)$, with statistically significant among all pharmaceutical degrees $(p<0.001)$. The total average scores of pharmacist feature elements of forensic pharmacy services were 2.5. The high scores element was forensic pharmacy and potential drug-drug interactions (1.42). On the contrary, the lowest score aspect of nuclear pharmacy was forensic pharmacy, education and training program (1.26). The average score of forensic pharmacy practice implementation was 3.15. With high scores was the pharmacist always parts in crimes medicine committee (3.74), while the lowest forensic pharmacy practice implementation scores were attendance several courses or workshops about forensic pharmacy (2.41). Conclusion: The pharmacist part elements or the practice applications of forensic pharmacy were insufficient. The pharmacist plays an active role in the forensic pharmacy practice. Recognized forensic pharmacy with a clear job description of pharmacy staff with the relationship with forensic medicine and forensic strategic planning is mandatory to improve forensic pharmacy services in Saudi Arabia.

Key words: Practice, Pharmacist, Forensic, Pharmacy, Saudi Arabia
\end{abstract}

\section{INTRODUCTION}

Forensic medicine is well recognised in the Kingdom of Saudi Arabia. ${ }^{[1,2]}$ Forensic medicine was started in the 1960s at the Ministry of Health in Saudi Arabia. ${ }^{[2]}$ Each region had one forensic medicine associated with higher administration. Each forensic medicine section had physicians dedicated in forensic medicine, nurses, related employment. There were annual reports about forensic medicine published through $\mathrm{MOH}$ statistical books published annually. ${ }^{[3,4]}$ They had a job description for each staff and policy and procedures of the department. They were an active member of the criminal and death committee. The education of forensic medicine is delivered through $60 \%$ of the college of medical universities. ${ }^{[1,5]}$ Currently, Saudi heath of specialties had four years of forensic medicine board. ${ }^{[6]}$ Forensic medicine is delivered through numerous countries, counting Egypt and Kuwait. ${ }^{[1]}$ Moreover, It includes well-developed, standardized, highly educated forensic medicine in the United Kingdom and the United States of America. ${ }^{[1,7-9]}$ However, a discretion survey about forensic medicine services was not printed in Saudi Arabia or Arabia countries. The practice training of forensic medicine is not typical during undergraduate studies. ${ }^{[5]}$ Forensic science takes care of all criminal or unexplained death of any adults or pediatrics. ${ }^{[2]}$ In comparison, the forensic pharmacy debated intentional medications related to morbidity and mortality counting the intentional poisoning and toxic material analysis in the forensic laboratories. The pharmacist offers many activities to forensic medicine practice. ${ }^{[10-13]}$ Various literature conversed the pharmacist and clinical pharmacist activities in the forensic services. Besides, a forensic pharmacy technician had been designated. Many basic activities should be employed during forensic pharmacy practice. That includes but is not limited to the vision and mission of forensic pharmacy, values, objectives, annual plan of forensic pharmacy. Besides, also entails policy and procedures of forensic pharmacy. For any forensic medicine, demand for forensic pharmacy services is to be applied. The forensic pharmacy activities implemented were not known in Saudi Arabia or Gulf countries, or the rest of the world. The current investigation deliberated the forensic pharmacy activities implementation in Saudi Arabia. 


\section{METHODS}

It analyses a cross-sectional survey that deliberated pharmacist's practice of forensic pharmacy in Saudi Arabia. It self-reported an electronic survey of dentists, counting pharmacists from internship to consultant, pharmacist specialties, and Saudi Arabia. All non- pharmacist or students and noncompleted surveys will be accepted from the study. The survey comprised of respondents' demographic information about pharmacists and practice knowledge of selected aspects for forensic pharmacy practice and implementation. The 5-point Likert response scale system was applied with closed-ended questions. According to the previous literature with unlimited population size, the sample was planned as a cross-sectional study, the confidence level $95 \%$ with $\mathrm{z}$ score of 1.96 and margin of error 5-6.5\%, population percentage $50 \%$, and drop-out rate $10 \%$. As a result, the sample size will equal 480 to 420 with a power of study of $80 \% \cdot{ }^{[14-16]}$ The response rate compulsory calculated sample size to be measured at least $60-70 \%$ and above. ${ }^{[16,17]}$

The survey was dispersed through social media of what's applications and telegram groups of pharmacists. The prompt message had been sent every 1-2 weeks. The survey was authenticated through the revision of expert reviewers and pilot testing. Besides, numerous tests of reliability McDonald's $\omega$, Cronbach alpha, Guttmann's $\lambda 2$, and Guttmann's $\lambda 6$ had been done with the study. The data analysis of the pharmacist's practice of nuclear pharmacy is finished through the survey monkey system. Besides, the statistical package of social sciences (SPSS) and Jeffery's Amazing Statistics Program (JASP), Microsoft excel sheet version 16 with description and frequency analysis, good of fitness analysis, correlation analysis, and inferential analysis of factors marks pharmacist's practice of nuclear pharmacy. The STROBE (Strengthening the reporting of observational studies in epidemiology statement: guidelines for reporting observational studies) showed the reporting of the current study. ${ }^{[18,19]}$

\section{RESULTS}

The total number of responding pharmacists was 402, with most of them coming from the south area $252(62.69 \%)$ with statistically momentous among the regions $(p<0.001)$. Of those, 198 (49.75\%) were male, while $200(50.25 \%)$ were female, with statistical significance between them $(p<0.001)$. Most of the responders were in age (24-30) years 269 $(67.08 \%)$ with statistically important between all ages level $(p<0.001)$. Almost three-quarters of the pharmacists had bachelor's degrees 303 (75.56\%), with statistically significant among all pharmaceutical degrees $(p<0.001)$. The majority of responders worked at community pharmacy 124 (30.85\%), MOH hospitals 107 (26.62\%), and military hospitals 76 (18.91\%). Most pharmacists were staff pharmacists $284(70.65 \%)$, and half of the responders had practised three years and less 213 (53.25\%) with the majority of their practice at the community pharmacy $115 \quad(31.86 \%)$ and outpatient pharmacy $88 \quad(24.38 \%)$ with statistically significant between them $(p<0.001)$. There is a strong positive association between Age (years) and Years of experience at pharmacy career Kendall's tau_b (0.699) or Spearman's rho $(0.747)$ with statistically significant difference $(p<0.001)$. On the other hand, there is a negative medium correlation between position and age or Years of experience at pharmacy career with Kendall's tau_b (-0.447) or Spearman's rho $(-0.488)$ or Kendall's tau_b $(-0.460)$ or Spearman's rho $(-0.511)$ respectively with statistically significant difference $(p>0.05)$ as reconnoitred in Table 1 and 2.

The total average scores of pharmacist aspect elements of forensic pharmacy services were 2.5. The high scores element was forensic pharmacy and potential drug-drug interactions (1.42), forensic pharmacy and medications errors system (1.39), and forensic pharmacy and drug quality reporting system (1.39). On the contrary, the lowest score facet of nuclear pharmacy was forensic pharmacy and education and training program (1.26), the vision of forensic pharmacy (1.29), and the strategic plan of forensic pharmacy (1.29) with statistically significant between answers $(p<0.001)$ as explored in Table 3. The average score of forensic pharmacy practice implementation was 3.15. With high scores was the pharmacist always shares in crimes medicine committee (3.74), the clinical pharmacist had an active role in forensic medicine departments (3.55), and the pharmacist share in forensic medicine committee (3.53). In contrast, the lowest forensic pharmacy practice implementation scores were attend several courses or workshops about forensic pharmacy (2.41), and there is electronic forensic pharmacy (2.74). Besides, there are numerous forensic pharmacy resources in practice (2.80) with statistically significant differences between answers $(p<0.001)$ as explored in Table 4 . The highest score Forensic pharmacy (to authorities) currently is the responsibility was a forensic pharmacist (4.43) and forensic medicine doctors (3.62). In contrast, the lowest score was forensic nurses (2.98), with a statistically noteworthy difference between them $(p<0.001)$

\begin{tabular}{|c|c|c|c|}
\hline Nationality & Response Count & Response Percent & p-value (X2) \\
\hline Central area & 72 & $17.91 \%$ & \multirow[t]{5}{*}{$<0.001$} \\
\hline North area & 24 & $5.97 \%$ & \\
\hline South area & 252 & $62.69 \%$ & \\
\hline East area & 11 & $2.74 \%$ & \\
\hline West area & 43 & $10.70 \%$ & \\
\hline Answered question & 402 & & \\
\hline Skipped question & $\mathbf{0}$ & & \\
\hline Gender & Response Count & Response Percent & \\
\hline Male & 198 & $49.75 \%$ & \multirow[t]{2}{*}{$<0.001$} \\
\hline Female & 200 & $50.25 \%$ & \\
\hline Answered question & 398 & & \\
\hline Skipped question & 4 & & \\
\hline Age & Response Count & Response Percent & \\
\hline $24-30$ & 269 & $67.08 \%$ & \multirow[t]{6}{*}{$<0.001$} \\
\hline $31-35$ & 73 & $18.20 \%$ & \\
\hline $36-40$ & 28 & $6.98 \%$ & \\
\hline $41-45$ & 9 & $2.24 \%$ & \\
\hline $46-50$ & 8 & $2.00 \%$ & \\
\hline$>50$ & 14 & $3.49 \%$ & \\
\hline Answered question & 401 & & \\
\hline Skipped question & 1 & & \\
\hline
\end{tabular}




\begin{tabular}{|c|c|c|c|}
\hline $\begin{array}{l}\text { Pharmacist } \\
\text { Qualifications }\end{array}$ & $\begin{array}{l}\text { Response } \\
\text { Count }\end{array}$ & $\begin{array}{l}\text { Response } \\
\text { Percent }\end{array}$ & $\begin{array}{l}\text { p-value } \\
\text { (X2) }\end{array}$ \\
\hline MOH Hospitals & 107 & $26.62 \%$ & \\
\hline Military hospitals & 76 & $18.91 \%$ & \\
\hline National Gaurd Hospital & 11 & $2.74 \%$ & \\
\hline Security forces hospitals & 4 & $1.00 \%$ & \\
\hline University hospital & 12 & $2.99 \%$ & \\
\hline $\begin{array}{l}\mathrm{MOH} \text { primary care } \\
\text { centers }\end{array}$ & 15 & $3.73 \%$ & \\
\hline Private hospitals & 12 & $2.99 \%$ & \\
\hline $\begin{array}{l}\text { Private ambulatory care } \\
\text { clinics }\end{array}$ & 1 & $0.25 \%$ & \\
\hline $\begin{array}{l}\text { Private primary healthcare } \\
\text { center }\end{array}$ & 6 & $1.49 \%$ & \\
\hline Community pharmacy & 124 & $30.85 \%$ & \\
\hline Pharmaceutical company & 15 & $3.73 \%$ & \\
\hline University (Academia) & 9 & $2.24 \%$ & \\
\hline Retried & 2 & $0.50 \%$ & \\
\hline Un-employment & 8 & $1.99 \%$ & \\
\hline Answered question & 402 & & \\
\hline Skipped question & $\mathbf{0}$ & & \\
\hline Academic Qualifications & $\begin{array}{l}\text { Response } \\
\text { Count }\end{array}$ & $\begin{array}{l}\text { Response } \\
\text { Percent }\end{array}$ & \\
\hline Diploma in Pharmacy & 29 & $7.23 \%$ & \\
\hline Bachelor's in pharmacy & 303 & $75.56 \%$ & \\
\hline Master & 47 & $11.72 \%$ & \\
\hline Pharm D & 73 & $18.20 \%$ & \\
\hline Ph. D & 9 & $2.24 \%$ & \\
\hline PGY 1 & 6 & $1.50 \%$ & \\
\hline PGY 2 & 8 & $2.00 \%$ & \\
\hline PGY 3 & 4 & $1.00 \%$ & \\
\hline Fellowship & 1 & $0.25 \%$ & \\
\hline Other (please specify) & 0 & $0.00 \%$ & \\
\hline Answered question & 401 & & \\
\hline Skipped question & 1 & & \\
\hline Position Held & $\begin{array}{l}\text { Response } \\
\text { Count }\end{array}$ & $\begin{array}{c}\text { Response } \\
\text { Percent }\end{array}$ & \\
\hline Director of Pharmacy & 18 & $4.48 \%$ & $<0.001$ \\
\hline $\begin{array}{l}\text { Assistant Director of } \\
\text { Pharmacy }\end{array}$ & 18 & $4.48 \%$ & \\
\hline Supervisor & 32 & $7.96 \%$ & \\
\hline Pharmacy staff & 284 & $70.65 \%$ & \\
\hline Pharmacy Intern & 50 & $12.44 \%$ & \\
\hline Answered question & 402 & & \\
\hline Skipped question & 0 & & \\
\hline
\end{tabular}

continued...

\begin{tabular}{|c|c|c|c|}
\hline $\begin{array}{l}\text { Years of experience at } \\
\text { Physician career }\end{array}$ & $\begin{array}{l}\text { Response } \\
\text { Count }\end{array}$ & $\begin{array}{c}\text { Response } \\
\text { Percent }\end{array}$ & \\
\hline Less than one year & 213 & $53.25 \%$ & \multirow[t]{6}{*}{$<001$} \\
\hline $1-3$ & 87 & $21.75 \%$ & \\
\hline $4-6$ & 41 & $10.25 \%$ & \\
\hline 7-9 & 15 & $3.75 \%$ & \\
\hline 10-12 & 12 & $3.00 \%$ & \\
\hline$>12$ & 32 & $8.00 \%$ & \\
\hline Answered question & 400 & & \\
\hline Skipped question & 2 & & \\
\hline The practice area & $\begin{array}{l}\text { Response } \\
\text { Count }\end{array}$ & $\begin{array}{c}\text { Response } \\
\text { Percent }\end{array}$ & \\
\hline Inpatient Pharmacy & 46 & $12.74 \%$ & \multirow[t]{18}{*}{$<001$} \\
\hline Outpatient Pharmacy & 88 & $24.38 \%$ & \\
\hline Satellite Pharmacy & 3 & $0.83 \%$ & \\
\hline Narcotics and Controlled & 4 & $1.11 \%$ & \\
\hline $\begin{array}{l}\text { Extemporaneous } \\
\text { Preparation }\end{array}$ & 1 & $0.28 \%$ & \\
\hline Clinical Pharmacy & 46 & $12.74 \%$ & \\
\hline Inventory Control & 8 & $2.22 \%$ & \\
\hline Drug Information & 5 & $1.39 \%$ & \\
\hline IV admixture & 11 & $3.05 \%$ & \\
\hline Pharmacy informatics & 1 & $0.28 \%$ & \\
\hline $\begin{array}{l}\text { Hospital Pharmacy } \\
\text { administration }\end{array}$ & 4 & $1.11 \%$ & \\
\hline Forensic medicine & 1 & $0.28 \%$ & \\
\hline Community pharmacy & 115 & $31.86 \%$ & \\
\hline Lecturer (Academia) & 2 & $0.55 \%$ & \\
\hline Pharmaceutical company & 14 & $3.88 \%$ & \\
\hline Non-specific & 12 & $3.32 \%$ & \\
\hline Answered question & 361 & & \\
\hline Skipped question & 41 & & \\
\hline
\end{tabular}

as explored in Table 5. The majority of responders did not work in forensic pharmacy 369 $(92.02 \%)$, there is no statically significant differences between all practice or did not practice forensic pharmacy or answered by they do not distinguish and all aspect of forensic pharmacy or implantation $(p>0.05)$. The reliability test of McDonald's $\omega$, 0.892, Cronbach alpha 0.894, Guttmann's $\lambda 2$, 0.911, and Guttmann's $\lambda 6,0.966$.

Factors manipulating the items forensic pharmacy practice (average scores). The various factor might impact the forensic pharmacy practice. Using independent samples KruskalWallis test and the Bonferroni correction for multiple tests have adjusted significant values, the results showed as follows. The various factor might impact the forensic pharmacy practice. Five locations exaggerated the forensic pharmacy practice, with south the lowest average score (1.1714) with statically significant differences $(p=0.000)$, while it is not statically momentous with forensic pharmacy practice implementation $\quad(p=0.544)$. Thirteen levels of work pretentious the aspects of forensic pharmacy practice with 


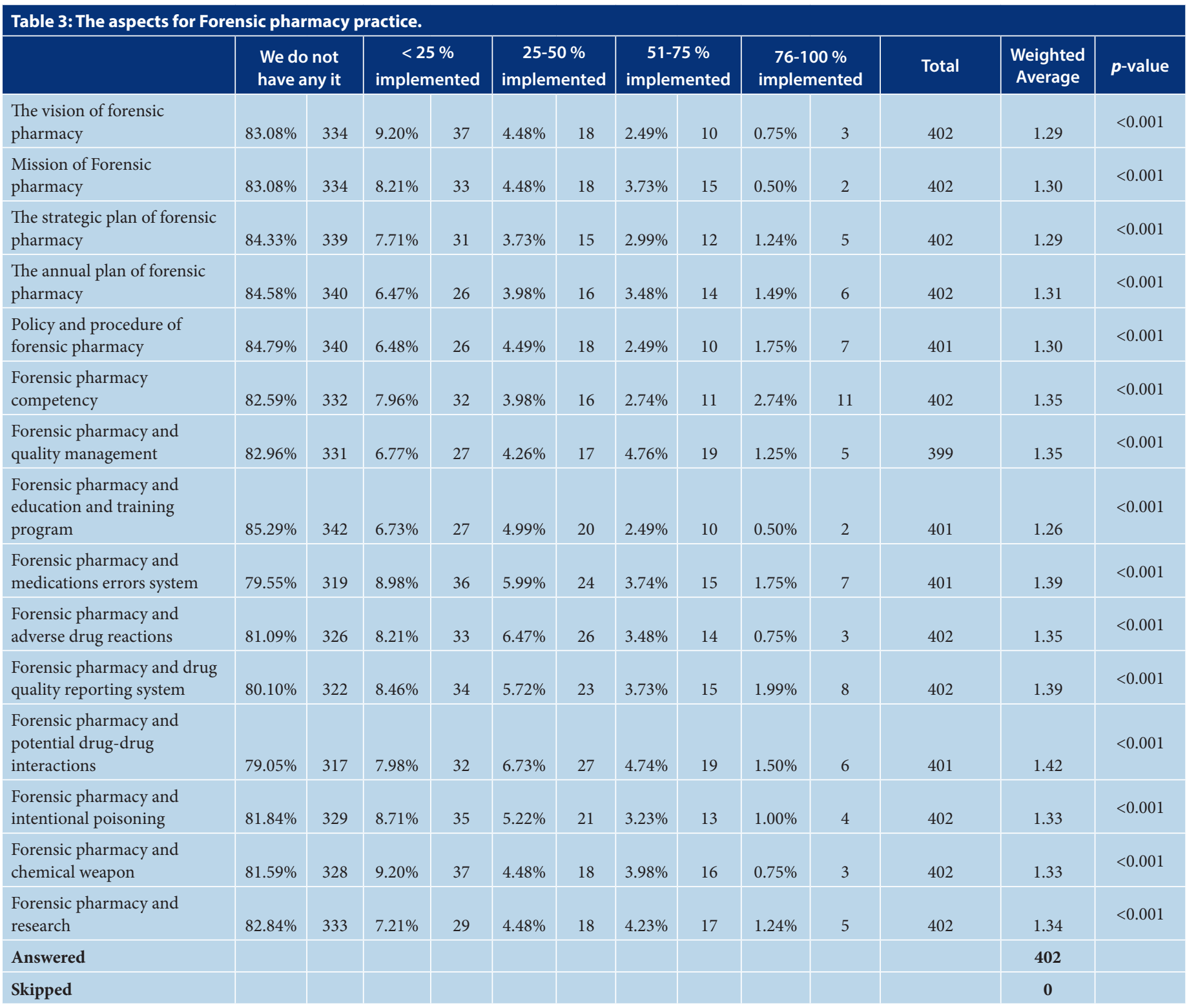

statically significant differences $(p=0.000)$. In comparison, there is not statically significant with forensic pharmacy practice implementation $(p=0.060)$. Six levels of age affected forensic pharmacy practice and forensic pharmacy practice implementation with statically significant differences $(p=0.027)$ and ( $p=0.013)$ respectively as generally, there is not any precise age for significant differences. There are not statically significant differences in the persuading the Forensic pharmacy basic knowledge in gender $(p=0.000)$. There are no statically significant differences in controlling the Forensic pharmacy practice and Forensic pharmacy practice implementation in gender $(p=0.282)$. Five levels of a position affected forensic pharmacy practice and implementation with statically significant differences $(p=0.000)$ and $(p=0.003)$, respectively. There is no exact position that had significant differences. Finally, six levels of experience affected the Forensic pharmacy practice and forensic pharmacy practice implementation with nonstatically significant differences $(p=0.182)$ and ( $p=0.176)$, respectively, as explored in Table 6.

The relationship between the practice aspect of forensic pharmacy and factors location, site of work, age (years), pharmacist gender, years of experiences at pharmacy career and position Held, established through a multiple regression model and measured the practice facet of Forensic pharmacy dependent variable and factors were observed as an expletory variable. A weak relationship was $\mathrm{R}$ (0.182) with $(\mathrm{p}=0.041)$ between forensic pharmacy practice and factors. All factors were non-significant differences $(p>0.05)$. However, there was one factor only; the position held elucidated
$13.4 \%(\mathrm{p}=0.018)$ of a negative connection and variation in the preparation of nuclear pharmacy implementation with a statistically significant $\quad(\mathrm{p}<0.05) \quad$ through multiple regression model and established by Bootstrap model. The relationship among practice aspect of Forensic pharmacy and one factor verified by the non-existence of multicollinearity with the position held factor (VIF=3.212) almost nearest three or less than ten ${ }^{[20,21,22]}$ as explored in Table 7.

The relationship between advanced forensic pharmacy practice implementation and factors location, site of work, age (years), pharmacist gender, Years of experience in pharmacy career, and Position Held. It was verified through a multiple regression model and measured the forensic pharmacy practice implementationdependent factors were regarded as the 


\begin{tabular}{|c|c|c|c|c|c|c|c|c|c|c|c|c|c|}
\hline \multirow{2}{*}{$\begin{array}{l}\text { The pharmacist always active } \\
\text { member in the mortality committee } \\
\text { at healthcare institutions }\end{array}$} & \multicolumn{2}{|c|}{$\begin{array}{l}\text { Strongly } \\
\text { disagree }\end{array}$} & \multicolumn{2}{|c|}{ Disagree } & \multicolumn{2}{|c|}{ Uncertain } & \multicolumn{2}{|c|}{ Agree } & \multicolumn{2}{|c|}{ Strongly agree } & \multirow{2}{*}{$\begin{array}{l}\text { Total } \\
401\end{array}$} & \multirow{2}{*}{$\begin{array}{c}\text { Weighted } \\
\text { Average } \\
3.52\end{array}$} & \multirow[b]{2}{*}{$<0.001$} \\
\hline & $5.74 \%$ & 23 & $4.49 \%$ & 18 & $41.15 \%$ & 165 & $28.93 \%$ & 116 & $19.70 \%$ & 79 & & & \\
\hline $\begin{array}{l}\text { The pharmacist share in forensic } \\
\text { medicine committee }\end{array}$ & $4.99 \%$ & 20 & $4.99 \%$ & 20 & $41.65 \%$ & 167 & $28.68 \%$ & 115 & $19.70 \%$ & 79 & 401 & 3.53 & $<0.001$ \\
\hline $\begin{array}{l}\text { The pharmacist always shares in } \\
\text { crimes medicine committee }\end{array}$ & $4.73 \%$ & 19 & $2.74 \%$ & 11 & $31.34 \%$ & 126 & $36.57 \%$ & 147 & $24.63 \%$ & 99 & 402 & 3.74 & $<0.001$ \\
\hline $\begin{array}{l}\text { The pharmacist had clear job } \\
\text { descriptions in forensic medicine } \\
\text { departments }\end{array}$ & $14.21 \%$ & 57 & $8.73 \%$ & 35 & $43.64 \%$ & 175 & $19.70 \%$ & 79 & $13.72 \%$ & 55 & 401 & 3.10 & $<0.001$ \\
\hline $\begin{array}{l}\text { There is documentation of potential } \\
\text { impact and outcomes with forensic } \\
\text { medicine }\end{array}$ & $14.79 \%$ & 59 & $12.78 \%$ & 51 & $47.87 \%$ & 191 & $15.04 \%$ & 60 & $9.52 \%$ & 38 & 399 & 2.92 & $<0.001$ \\
\hline $\begin{array}{l}\text { I attended several courses or } \\
\text { workshops about Forensic } \\
\text { pharmacy }\end{array}$ & $30.40 \%$ & 121 & $17.59 \%$ & 70 & $37.44 \%$ & 149 & $10.05 \%$ & 40 & $4.52 \%$ & 18 & 398 & 2.41 & $<0.001$ \\
\hline $\begin{array}{l}\text { There is electronic forensic } \\
\text { pharmacy }\end{array}$ & $18.70 \%$ & 75 & $10.47 \%$ & 42 & $55.11 \%$ & 221 & $9.98 \%$ & 40 & $5.74 \%$ & 23 & 401 & 2.74 & $<0.001$ \\
\hline $\begin{array}{l}\text { There are various of forensic } \\
\text { pharmacy resources in the practice }\end{array}$ & $11.94 \%$ & 48 & $15.42 \%$ & 62 & $58.21 \%$ & 234 & $9.70 \%$ & 39 & $4.73 \%$ & 19 & 402 & 2.80 & $<0.001$ \\
\hline
\end{tabular}

\begin{tabular}{|l|l|l|l|l|l|l|l|l|l|l|l|l|}
\hline Table 5: The forensic pharmacy (to authorities) currently is the responsibility of the following. \\
\hline
\end{tabular}

expletory variable. There was a weak relationship R ( 0.372$)$ with $(p=0.000)$ between forensic pharmacy practice implementation and factors with non-statistically significant difference $(p>0.05)$. Besides, the relationship established by through Standardized Coefficients Beta through multiple regression model and long-established by Bootstrap model as explored in Table 8.

\section{DISCUSSION}

The description of forensic pharmacy is an essential step to create it. ${ }^{[10,12]}$ The practice contained of aspects of forensic pharmacy and some fundamental elements of implementation and responsibility of the forensic pharmacy services and relationships with forensic medicine. The existing examination will discover the forensic pharmacy practice with tolerable convenience sample size, good validation by the expert reviewer, and a highreliability test. Most of the responders from the South region is the place most authors had lived. The majority of responders were from a community pharmacy or hospital pharmacist with an almost equal gender to imitate those practices. Most of the responders were young pharmacists with a bachelor's degree and less than three years of experience expected to reproduce the actual current of a forensic pharmacy career. The young pharmacist is getting experiences. However, the young pharmacist is getting higher 


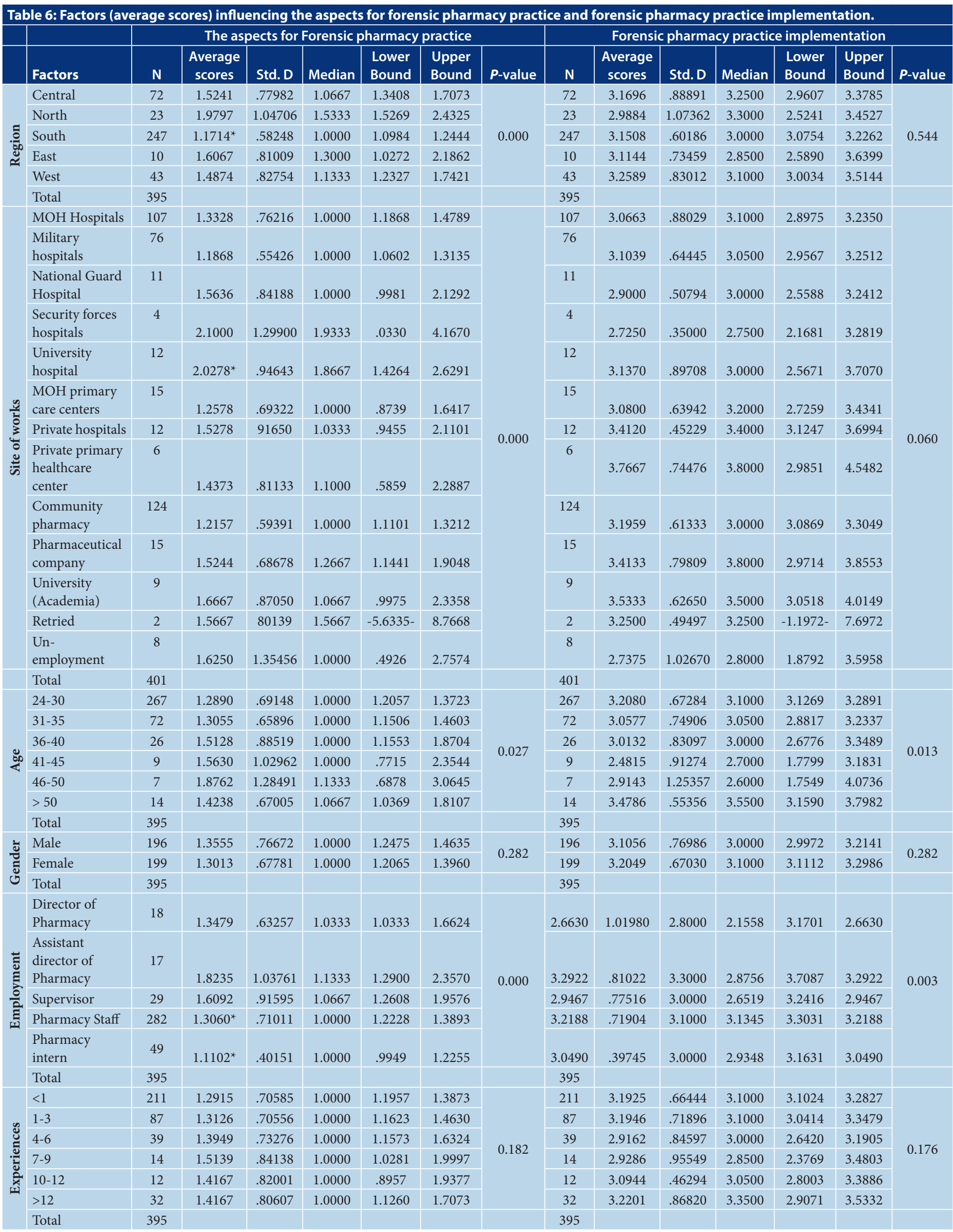




\begin{tabular}{l} 
Table 7: Multiple regression of Factors with the aspects for Forensic pharmacy practice. \\
\hline
\end{tabular}

a. Dependent Variable: Nuclear pharmacy basic knowledge, Predictors: (Constant), Location, Age (years), Pharmacist gender, Position Held, and Years of experiences at pharmacy career.

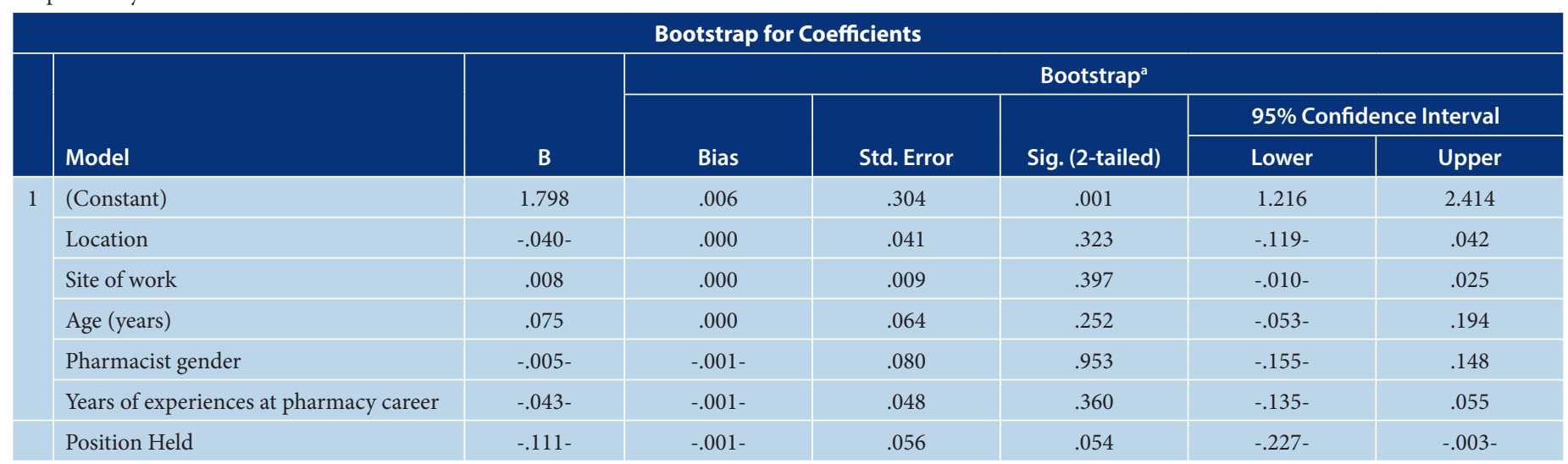

a. Unless otherwise noted, bootstrap results are based on 1000 bootstrap samples

position employment due to their availability and desirable than pharmacy technician. The current search showed that the average scores of aspect forensic pharmacy were not satisfactory. The most practical elements of forensic pharmacy were drug-drug interaction, medications error system, and drug quality reporting system. ${ }^{[23,24]}$ All those aspects were mandatory for the Saudi Center of healthcare accreditation in Saudi Arabia. ${ }^{[25]}$

In comparison, the rare practice of forensic pharmacy was education and training of forensic pharmacy, vision, and strategic plan. That is, no complete program of forensic pharmacy was implemented. The study results showed that the average score of forensic pharmacy practice implementation was neutral. The most practical activities implemented were the pharmacist participated in the crimes and forensic medicine committees, and the pharmacist had a role in the forensic medicine department. That might be implemented at some hospitals or some forensic medical sections. However, it was not expected at all healthcare institutions.

On the contrary, the rare activities executed attended lectures or workshops about forensic pharmacy resembling earlier forensic medicine studies. ${ }^{[26]}$ Besides, electronic forensic pharmacy systems at their institutions and the availability of forensic pharmacy resources in the institution's library. The forensic pharmacy system desires more focus to review it and update it thoroughly. All responders are highly suggested that pharmacists should be responsible for forensic pharmacy, not physicians or nurses that is expected for responder pharmacists and more opinions from physicians and nurses in future studies. Most responders were not committed at forensic pharmacies, resemble previous forensic medicine studies. ${ }^{[5]}$ However, the biostatistics analysis displayed no statistically significant difference between had practice experiences or not in answering all elements of forensic pharmacy practice aspects. It is mainly the vision of forensic pharmacy was not clear, or the program was not started in practice.

Various factors exaggerated the aspects of the practice of forensic pharmacy or the implementation of forensic pharmacy. The location might move the aspect practice of forensic pharmacy with prominence on the south region having the lowest score related to most of the aspects not found in their area. In contrast, the location did not affect the implementation of forensic pharmacy. The work site was another factor that had almost high scores at university hospitals linked to the might aspect of forensic pharmacy found there and its need for teaching medical or pharmacy students. On the contrary, the site of work did not affect forensic pharmacy employment. The age was another one that affected both forensic pharmacy and implementation aspects without clear which age of group might affect them related to sample size by comparing the average score of all ages among both facets of forensic pharmacy and implementation. The elements score lower than the implementation 


\begin{tabular}{|l|l|l|l|l|l|l|l|l|l|l|l|l|}
\hline \multicolumn{2}{|c|}{ Table 8: Multiple regression of Factors with the Forensic pharmacy practice implementation. } \\
\hline
\end{tabular}

a. Dependent Variable: Nuclear pharmacy basic knowledge, Predictors: (Constant), Location, Age (years), Pharmacist gender, Position Held, and Years of experiences at pharmacy career.

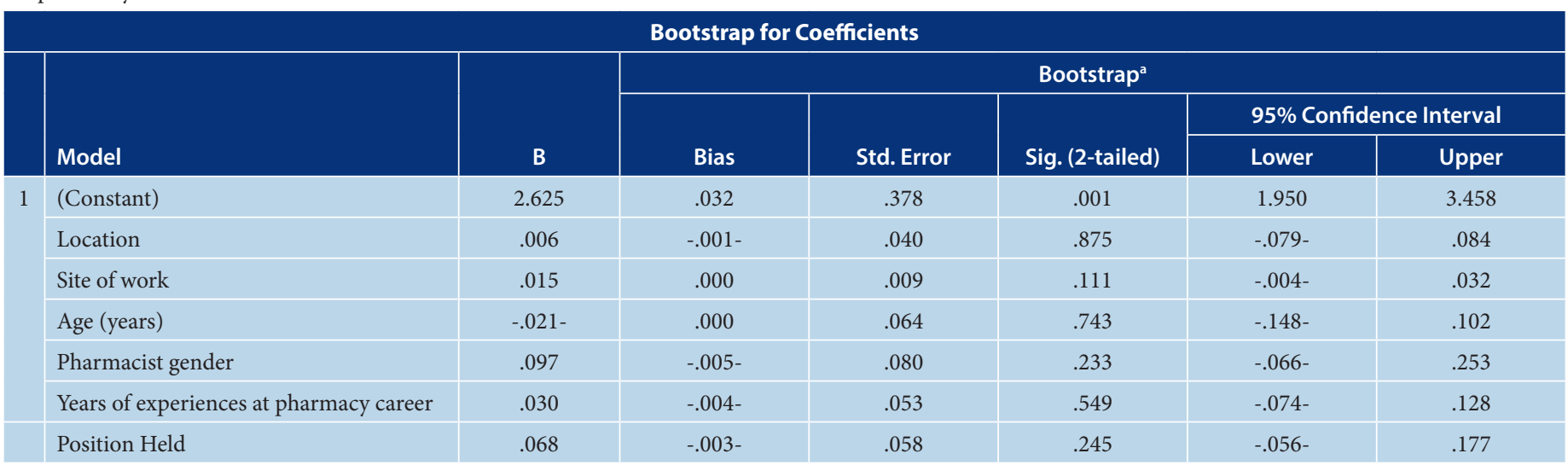

a. Unless otherwise noted, bootstrap results are based on 1000 bootstrap samples

of forensic pharmacy related to diverse opinions, or the survey was not very clear for them. Gender does not affect the aspect and performance of forensic pharmacy. The position factors can affect parts of forensic pharmacy with the lowest score of pharmacy intern and pharmacy staff, which is expected because they were newly graduated and need more time to gain more practice knowledge at the forensic pharmacy. The position might affect forensic pharmacy implementation with clears, which position in pharmacy career can mark more due to sampling size. Besides, the job was affected negatively by $13.4 \%$, with each one surge of work. Higher position cause lower aspect of forensic pharmacy. The number of years of experience does not affect the element of forensic pharmacy or implementation. There was not any connection between all factors and forensic pharmacy implementation scores.

\section{Limitations}

Although the existing survey stated critical information in forensic pharmacy and implementation, there were numerous limitations including the sampling method. It was the convenient sample. The sample checked unequal distribution of responders per geographic location, unequal age distribution, and most demographic information with statistically significant differences. Most responders were young, recently graduated, and worked in community pharmacy. As a result, the study results have not imitated all types of the hospital or forensic pharmacists or age level or experiences. Further studies mandatory comparable demographic data in highly acclaimed. The research about forensic pharmacy practice is rare or non-existent, and it was difficult to compare the study results with previous studies.

\section{CONCLUSION}

The practice of forensic pharmacy was inadequate. The majority of pharmacists work in forensic pharmacy through potential drugdrug interactions in forensic sciences, forensic pharmacy, medications errors systems, and drug quality reporting systems. No numerous factors predisposed the forensic pharmacy practice except position career number only. The number of forensic pharmacy staff should be augmented and involved in forensic medicine. Further study of forensic medicine and pharmacy services in-depth detail was necessitated to setup up a strategic plan and improve forensic pharmacy practice in Saudi Arabia.

\section{ACKNOWLEDGEMENT}

None.

\section{CONFLICT OF INTEREST}

The authors declare that there is no conflict of interest.

\section{Funding}

None 


\section{Consent for Publications}

Informed consent was obtained from all the participants

\section{Ethical Approval}

This research was exempted from research and ethical committee or an institutional review board (IRB) approval.

https://www.hhs.gov/ohrp/regulations-andpolicy/decision-charts-2018/index.html

\section{ABBREVIATIONS}

MOH: Ministry of Health; KSA: Kingdom of Saudi Arabia; SPSS: Statistical Package of Social Sciences; JASP: Jeffery's Amazing Statistics Program; Strobe: Strengthening the reporting of observational studies in epidemiology statement: guidelines for reporting observational studies; SFDA: Saudi Food and Drug Authority; CBAHI: Saudi Central Board for Accreditation of Healthcare Institutions.

\section{ORCID ID}

Yousef Ahmed Alomi (iD https://orcid. org/0000-0003-1381-628X

\section{REFERENCES}

1. Al-Waheeb S, Al-Kandary N, Aljerian K. Forensic autopsy practice in the Middle East: comparisons with the west. J Forensic Leg Med. 2015;32:4-9. doi: 10.1016/j.jflm.2015.02.003, PMID 25882141.

2. Al Madani OM, Kharoshah MAA, Zaki MK, Galeb SS, Al Moghannam SA, Moulana AAR. Origin and development of forensic medicine in the Kingdom of Saudi Arabia. Am J Forensic Med Pathol. 2012;33(2):147-51. doi: 10.1097/ PAF.0b013e318221b895, PMID 21725228.

3. Saudi Ministry of Health. Kingdom of Saudi Arabia statistical year. Bk. 2016; 2016.

4. Saudi Ministry of Health. Kingdom of Saudi Arabia annual statistical. Bk. 2017; 2017.

5. Madadin M, Al-Saif DM, Khamis AH, Taha AZ, Kharoshah MA, Alsayyah A, Alfehaid S, Yaghmour K, Hakami AY, Bamousa MS, Menezes RG, Almadani OM. Undergraduate teaching of forensic medicine in Saudi Arabia. Med Sci Law. 2016:56(3):163-6. doi: 10.1177/0025802416653584, PMID 27354384.

6. Saudi Commission for Health Specialties. Saudi board forensic Medicine Curriculum; 2018.

7. Vanezis P. Forensic medicine: past, present, and future. Lancet. 2004;364;Suppl 1:s8-9. doi: 10.1016/S0140-6736(04)17620-4, PMID 15967132.

8. Wilson-Wilde L. The international development of forensic science standards - a review. Forensic Sci Int. 2018;288:1-9. doi: 10.1016/j. forsciint.2018.04.009, PMID 29705583.

9. Tregar KL, Proni G. A review of forensic science higher education programs in the United States: Bachelor's and master's degrees. J Forensic Sci. 2010;55(6):1488-93. doi: 10.1111/j.15564029.2010.01505.x, PMID 20681966

10. Anderson PD. An overview of forensic pharmacist's practice. J Pharm Pract. 2000;13(3):179-86.

11. Anderson PD, Bokor G. Forensic aspects of druginduced violence. J Pharm Pract. 2012;25(1):41-9. doi: 10.1177/0897190011431150, PMID 22215647

12. Anderson PD. The broad field of forensic pharmacy. J Pharm Pract. 2012;25(1):7-12. doi: 10.1177/0897190011431144, PMID 22251569.

13. Anderson PD, O'Donnell JT. Specific forensic applications for pharmacists. J Pharm Pract. 2000;13(3):187-93. doi: 10.1177/ 089719000001300305.

14. Charan J, Biswas T. How to calculate sample size for different study designs in medical research? Indian J Psychol Med. 2013;35(2):121-6. doi: 10.4103/0253-7176.116232, PMID 24049221.

15. Pourhoseingholi MA, Vahedi M, Rahimzadeh $M$. Sample size calculation in medical studies. Gastroenterol Hepatol Bed Bench. 2013;6(1):14-7. PMID 24834239.

16. Ezhumalai DG. How Big A Sample Do I Require? Annals of SBV. 2017;6(1):39-41. doi: 10.5005/jpjournals-10085-6113.

17. Johnson TP, Wislar JS. Response rates and nonresponse errors in surveys [internet]. JAMA. 2012;307(17):1805-6. doi: 10.1001/ jama.2012.3532, PMID 22550194.

18. von Elm E, Altman DG, Egger M, Pocock SJ, Gøtzsche PC, Vandenbroucke JP. The strengthening the reporting of observational studies in epidemiology (STROBE) statement: guidelines for reporting observational studies. PLOS Med. 2007;4(10):1623-7. doi: 10.1371/journal. pmed.0040296.

19. Von Elm E, Altman DG, Egger M, Pocock SJ, Gøtzsche PC, Vandenbroucke JP. The Strengthening the Reporting of Observational Studies in Epidemiology (STROBE) statement: guidelines for reporting observational studies [internet]. Vol. 370; 2007. Available from: http://www.thelancet. com. Available from: http://www.plosmedicine. org [cited 19/8/2021].

20. Liao $D$, Valliant $R$. Variance inflation factors in the analysis of complex survey data. Surv Methodol. 2012;38(1):53-62.

21. Akinwande MO, Dikko HG, Samson A. Variance Inflation Factor: As a Condition for the Inclusion of Suppressor Variable(s) in Regression Analysis. Open J Stat. 2015;05(07):754-67.

22. Thompson CG, Kim RS, Aloe AM, Becker BJ. Extracting the Variance In flation Factor and Other Multicollinearity Diagnostics from Typical Regression Results. Basic Appl Soc Psych. 2017;39(2):81-90.

23. Alomi YA, Alghamdi SJ, Alattyh RA. National medication errors reporting system at Ministry of Health in Saudi Arabia. PTB Reports. 2019;5(1):4-7. doi: 10.5530/PTB.2019.5.2.

24. Alomi YA, Kamal E. National drug quality reporting system at Ministry of Health in Saudi Arabia. J Pharmacovigil. 2016;4(3). doi: 10.4172/23296887.1000208

25. Medication management system. Saudi Center Board for Accreditation for Healthcare Institutions (CBAHI). 2016.

26. Abdul NS, Alhazani L, Alruwail R, Aldres S, Asil S Awareness of forensic odontology among undergraduate, graduate, and postgraduate dental students in Riyadh, Saudi Arabia: A knowledge-, attitude-, and practice-based study. J Forensic Dent Sci. 2019;11(1):35-41. doi: 10.4103/jfo. jfds_52_19, PMID 31680754 